\title{
Gender Perspective on Drivers of Cigarette Smoking: Two Part Model Approach
}

\author{
Peter Kipkorir ${ }^{a^{*}}$, Vincent Ngeno ${ }^{a}$, Alfred Serem ${ }^{\text {a }}$ \\ ${ }^{a}$ Department of Agricultural Economics and Resource Management, Moi University, Kenya.
}

Received 10 January 2019; Accepted 25 February 2019

\begin{abstract}
An estimated 2.5 million Kenyans which is over 11 percent of the country's adult population currently use tobacco thus informing the need to take strong action to reduce tobacco use. Therefore, this study conducted a gender analysis on drivers of cigarette smoking in Kenya. The study heavily relied on data from Kenya Global Adult Tobacco Survey 2014. Specifically, two-part model was used to establish the effect of demographic and psychosocial drivers on both smoking participation and intensity among men and women. The study found that price of cigarette had an insignificant effect on men participation in smoking while age and years spent in education had a significant and negative effect on women smoking participation. Smoking rules inside home had a negative effect on women participation in smoking while smoking policy at indoor work place had a negative and significant effect on men smoking participation. Overally, cigarette tax adjustment had a negative and significant effect on both men and women participation in smoking. Work status had a negative and very significant effect on both men and women smoking intensity. The findings, therefore, confirmed the significant effect of smoking policy and cigarette tax adjustment on both smoking participation and smoking intensity among men and women.
\end{abstract}

\section{Key Messages}

\section{$\underline{\text { State of scientific knowledge of the subject matter }}$}

- There is a drastic shift in cigarette smoking from the developed countries to the developing countries

- Smoking behaviour is regarded as male dominating habit

- Globally, price is the main determinant of cigarette smoking and increasing cigarette tax has proven to be the most effective tool in reducing cigarette use

Important knowledge gaps that exist

- There is no empirical research that compares the smoking participation and smoking intensities among men and women in Kenya

- There is little knowledge on the psychosocial factors of cigarette smoking in Kenya.

What this study adds

- It provides empirical evidence on comparison between smoking participation and smoking intensities among men and women in Kenya.

- It also establishes that there are other factors known as psychosocial drivers that influence cigarette smoking

- It also documents the marginal effects of demographic and psychosocial drivers on cigarette smoking among men and women.

Keywords: Kenya; Gender Perspective; Drivers; Cigarette Smoking; Two-part Model.

*Corresponding author: kipkorirp@ymail.com

do) http://dx.doi.org/10.28991/SciMedJ-2019-0101-2

$>$ This is an open access article under the CC-BY license (https://creativecommons.org/licenses/by/4.0/).

(C) Authors retain all copyrights. 


\section{Introduction}

An estimated 2.5 million Kenyans which is over 11 percent of the country's adult population currently use tobacco. This smoking rate is the highest in sub-Saharan Africa, underscoring the need for Kenya to take strong action to reduce tobacco use. According to WHO statistics, the tobacco prevalence rate among Kenyan adults (25 to 65 years) is estimated at 23 percent among youth aged 15 to 24 ; the prevalence rate is 4.9 percent for males and 0.7 percent for females [1]. For the Eastern Africa region, the prevalence rate is 29 percent for males and 4 percent for females.

Smoking causes a huge health and economic burden to society; this effect is even more pronounced for a developing country like Kenya. Despite the preventable nature of tobacco related deaths and the control of tobacco use, the number of tobacco related deaths in Kenya is still a health challenge. Every year, approximately 6,000 Kenyans die of tobacco-related diseases, while more than 220,000 children and more than 2,737,000 adults continue to smoke each day [2].

One of the most effective ways to control the high rate of cigarette smoking is to raise tobacco excise taxes [3]. As part of the tobacco control programme, The WHO-Framework Convention on Tobacco Control (FCTC) advocates implementing appropriate price and tax measures to reduce tobacco production and cigarette smoking. Many studies reveal that increasing the excise tax on tobacco will not only reduce cigarette smoking but also may facilitate the generation of more revenue to the government [4].

It is estimated that a large proportion of cigarette smokers in Kenya are low-income household heads or members and that cigarette expenditure constitutes a relatively higher rate of their total expenditure [5]. In other words, the burden of an excise tax on cigarettes is particularly likely to affect the poor, who make up more than 40 percent of the Kenyan population. In an effort to mitigate this problem, Kenya ratified the World Health Organization Framework Convention on Tobacco Control (WHO FCTC) in 2004. The treaty sets out guidelines for countries to intersectoral tobacco control measures at the national and county levels. In Kenya, the Tobacco Control Act (TCA) in 2007 was passed to address the production, sale, labelling, advertising, promotion and sponsorship of tobacco products.

The governments might choose to increase cigarette taxes in order to generate more revenue, reduce cigarette consumption among the poor and the youth, correct socio- economic inefficiencies and improve public health [3]. Moreover, there is a policy dilemma between public health concerns and the economic benefit of tobacco production. Tobacco use is a major preventable cause of premature deaths, diseases and disabilities, presently causing over 6 million deaths each year in the world and expected to cause over 10 million deaths yearly by 2030 . In the 20th century, the tobacco epidemic killed more than 100 million people worldwide. Unless current trends are changed, the vast majority of these deaths, $80 \%$, are projected to occur in the developing world [6].

Rationally, tobacco use is enemy number one among risk factors for non-communicable diseases. It is a widely and broadly established cause of cancer and also responsible for cardiovascular and chronic respiratory diseases [7]. It has been estimated that there are more than 1.3 billion smokers worldwide, with around $80 \%$ residing in low and middleincome countries. $10 \%$ of all deaths resulting from non-communicable diseases including cancer, cardiovascular, chronic respiratory diseases and diabetes are related to tobacco and most of these occur in these low and middleincome countries [4].

This paper, therefore, examined the drivers of cigarette smoking in Kenya using the gendered-approach where it breaks downs the smoking participation and smoking intensity among men and women by utilizing the two-equations model traditionally known as the two-step model.

\section{Literature Review}

Approximately 2.5 million adults in Kenya (11.6 percent of the adult population) currently use tobacco. Of great concern, one in five men (19.1\%) use tobacco. Approximately half of life time users will die of tobacco related diseases, many in their most productive years between the ages of 30 and 60. The majority of tobacco users start at young ages before they are fully aware of the dangers of tobacco. Over half of Kenyan smokers started smoking before the age of 20 and almost all started before the age of 25 [8].

According to the Kenyan fact sheet it was found out that $15.1 \%$ of current tobacco users were men with only $0.8 \%$ women. $6 \%$ overall in the sample were found to be daily tobacco smokers while current men cigarette smokers and daily men cigarette smokers were found to be $15.1 \%$ and $11.6 \%$ respectively. The overall former daily tobacco smokers were found to be $28.5 \%$ meaning that over a quarter of the Kenyan population is either using tobacco or have previously used tobacco and tobacco related products [9].

Moreover, literature evidently indicates that the demand for tobacco products do respond to changes in prices and other factors in spite of its addictive nature [10]. Yurekli and Zhang [11] found that income has either an insignificant effect or negative effect on demand for cigarettes. Chaloupka and Warner [12] found that the weighted mean income 
elasticity is 0.36 which is significantly greater than zero. They also found that the income elasticity for cigarettes fell over time.

Alan et al. [13] revealed that the prevalence and intensity (quantity) of cigarette use was higher among males compared to females across all countries. Males aged between 30 and 49 years smoked cigarettes at higher rates as compared to those younger or older than this age range. Among females, prevalence rates of smoked tobacco use increased steadily with age. There was no clear pattern regarding socio-economic status (SES) or urban and rural differences. The onset of cigarette smoking mostly occurs in late adolescence or early adulthood.

Busch et al. [14] found that compared to female-smokers, male-smokers spent less on housing and apparels. High prevalence of tobacco use coupled with a sizeable proportion of the family budget spent on its consumption has great implications on welfare of the public in general and the tobacco using households in particular. The opportunity cost of spending on cigarette is very high especially for poor households. Probability of various respiratory, vascular and neoplastic diseases and mortality rates are found to be higher among tobacco users compared to non-users [15]. Considering the fact that prevalence of all kinds of tobacco consumption is higher among poor income groups in India, it is argued that tobacco use has the potential to trap the poor in a vicious circle of poverty and ill health [16].

Chaloupka [3] investigated the price responsiveness of different socioeconomic groups on cigarette smoking and found out that the price elasticity of cigarette demand was greater for individuals with less than high school education. Those with at least high school education were found to be unresponsive to price changes. However, Separate estimates of price elasticity of smoking prevalence and smoking intensity were not available until 1998. Rani et al. [17] reported on his observation of Urban- rural disparity of cigarette smoking that there are higher levels of cigarette smoking among households in the rural areas as compared to households in urban areas.

The CDC (1998) also found that Blacks were more price responsive than whites with respect to smoking prevalence and less so with respect to smoking intensity. They also further observed that Hispanics were more price responsive than were the black and white populations both with respect to smoking prevalence and smoking intensity. As a way of regulating smoking, Zulu et al. [18] suggested that smoking should be taught earlier in schools to ensure children knows the effects of smoking from an early age.

\section{Data and Methods}

Data from household and individual questionnaires of the Kenya Global Adult Tobacco Survey 2014 was heavily relied on. The Kenya GATS 2014 was a cross-sectional survey covering all 47 counties. A three-stage cluster sampling design was employed. The first stage sampling involved the selection of sample clusters. The second stage involved the selection of households and the third staged involved the selection of individuals. A sample size of 4408 individuals was picked for analysis.

\section{Econometric Model Specification}

A two-part model developed by Cragg [19] was employed in this case to analyze the smoking participation and smoking intensity among men and women. This Cragg-type model was employed by Mao et al. [20] to study the demand for cigarettes in China. The two-part model assumes that individuals first decide whether they will smoke or not and then if they decide to smoke, they choose how much to smoke.

Therefore, the propensity to smoke (the decision to participate in smoking) and the intensity of the smoking habit (the number of cigarettes smoked conditional upon smoking) are modeled separately. The first part of the model is the probability model (Probit) which was used to estimate an individual's decision to smoke as a function of the demographic and psychosocial variables. Therefore, the first part of the model (smoking participation) is specified as follows:

$\operatorname{Pr}(\mathrm{Y}=1 \mid \mathrm{X})=\Phi\left(\mathrm{X}_{\mathrm{i}} \beta\right)=\int_{-\infty}^{\mathrm{X}_{\mathrm{i}} \beta} \frac{1}{\sqrt{2 \pi}} \exp \left(-\frac{1}{2} \mathrm{z}^{2}\right) \mathrm{dz}$

The expected value of the dependent variable takes on the following form:

$\mathrm{E}(\mathrm{Y} \mid \mathrm{X})=0 \mathrm{x}\left(1-\Phi\left(\mathrm{X}_{\mathrm{i}} \beta\right)\right)+1 \mathrm{x} \Phi\left(\mathrm{X}_{\mathrm{i}} \beta\right)=\Phi\left(\mathrm{X}_{\mathrm{i}} \beta\right)$

Where $X=k \times 1$ the vector of independent variables,

$\beta=k \times 1$ is the vector of coefficients corresponding to the explanatory variables;

$\Phi$ refers to the standard normal cumulative distribution function. 
The second part of the model used least squares technique to estimate average daily sticks of cigarettes consumed by smokers, where the dependent variable is the natural logarithm of the average daily cigarette smoking variable. Both parts of the Cragg model include the same set of independent variables. The conditional log-linear demand equation (smoking intensity) is specified as follows:

$\ln Q_{i}=\alpha_{0}+\alpha_{i} X_{i}+\varepsilon, Y$

Where: $\varepsilon=$ error term, $\ln Q_{i}=$ natural logarithm of average weekly cigarettes smoked for person $i, X=k \times 1$ vector of independent variables, $\alpha=k \times 1$ vector of coefficients.

\section{Descriptive Statistics}

Approximately $90.0 \%$ of the total sampled population was not smoking while the remaining $10.0 \%$ of the respondents were households with smoking habits. Out of the $90.0 \%$ of the sampled population who did not smoke, $49.0 \%$ were males while $51.0 \%$ were females. This implies that more females do not smoke as compared to males. Contrarily, $90.0 \%$ of the households with smoking habits were males whereas the remaining $10.0 \%$ were females. This is a clear indicator that smoking is male dominated behavior. The mean age for the overall sample population was 33.64 years while the mean age for the smokers was 41.10 years.

The average time spent by an individual in school is approximately 8.0 years. This implies that most of the people completed their primary education. Approximately $76.0 \%$ of respondents who smoke were either employed by government, self- employed or non-government employee, only $24.0 \%$ of the smokers were unemployed which comprised of the students and those not in the labour market (including homemakers, the disable and the retired). $31.0 \%$ of the total smoking sampled population were singles or rather the unmarried while $69.0 \%$ composed of the married (including the separated, divorced and widowed).

Overally, $93.0 \%$ of the smoking sample population reported that either smoking was allowed inside their homes or smoking was allowed inside their homes but with exceptions or smoking was never allowed inside their homes while $7.0 \%$ of the smoking sample stated that there were no rules on smoking inside their homes. Also, $88.0 \%$ of the smoking sample population who were working reported that there was a smoking policy in indoor work place.

About $89.0 \%$ of the smokers saw health warning labels on cigarette packages while approximately $30.0 \%$ read about anticigarette information on newspapers and magazines. Most of the respondents had the knowledge of cigarette smoking; it causes serious health problems. There was a substantial agreement perception between the overall sample and the smoking sample that cigarette smoking is very addictive, workplaces the remaining $12.0 \%$ stated that there was no smoking policy in indoor workplaces. Majority $(84.0 \%)$ of the sampled population was in favour of tax adjustment on price of cigarette in order to discourage smoking participation and also reduce smoking intensity among men and women.

Table 1. Definition of Variable

\begin{tabular}{|c|c|c|c|c|c|}
\hline \multirow[t]{2}{*}{ Variable } & \multirow[t]{2}{*}{ Definition } & \multicolumn{2}{|c|}{$\begin{array}{c}\text { Full Sample } \\
(\mathrm{N}=4408)\end{array}$} & \multicolumn{2}{|c|}{$\begin{array}{c}\text { Smokers Sample } \\
0^{10}\left(0^{\mathrm{a}}(\mathrm{N49})\right.\end{array}$} \\
\hline & & Mean & S.D $\mathbf{D}^{\mathbf{b}}$ & Mean & S.D \\
\hline Cigprice $^{\mathrm{c}}$ & Average consumption weighted price per pack of cigarettes & - & - & 97.98 & - \\
\hline Wlthndx ${ }^{d}$ & Wealth index-proxy of permanent income & 2.17 & 0.328 & 1.66 & 0.284 \\
\hline Cigs & Number of cigarette sticks consumed per smoker per week & - & - & 46.56 & 4.355 \\
\hline Gen & $1=$ respondent is male, $0=$ otherwise & 0.49 & 0.022 & 0.95 & 0.025 \\
\hline Age & Respondent's age in years & 33.64 & 0.654 & 41.10 & 1.321 \\
\hline Eduyears & Time spent in education in years & 7.54 & 0.298 & 7.98 & 0.487 \\
\hline Hhsz & Number of household size & 4.93 & 0.156 & 4.51 & 0.269 \\
\hline Mals $>=15$ & Number of males with 15 years and above & 1.53 & 0.049 & 1.48 & 0.097 \\
\hline Children & Number of children in a household & 2.15 & 0.103 & 1.91 & 0.167 \\
\hline RelAct & $1=$ respondent involved in religious activities, $0=$ otherwise & 0.90 & 0.037 & 0.92 & 0.045 \\
\hline Marstat & $1=$ married, $0=$ otherwise & 0.72 & 0.029 & 0.69 & 0.073 \\
\hline Wokstat & $1=$ employed, $0=$ otherwise & 0.84 & 0.026 & 0.76 & 0.088 \\
\hline SPolicy & $1=$ respondent has Smoking policy at in indoor work place, $0=$ otherwise & 0.88 & 0.012 & 0.80 & 0.060 \\
\hline SRules & $1=$ respondent has smoking rules inside homes, $0=$ otherwise & 0.94 & 0.014 & 0.93 & 0.072 \\
\hline HWLCgPkg & $1=$ respondent saw health warning labels on cigarette packages, $0=$ otherwise & 0.66 & 0.028 & 0.89 & 0.037 \\
\hline ATC2007 & $1=$ respondent is aware of the Tobacco Control Act of $2007,0=$ otherwise & 0.63 & 0.026 & 0.64 & 0.069 \\
\hline
\end{tabular}




\begin{tabular}{|c|c|c|c|c|c|}
\hline AntiCig & $\begin{array}{l}1=\text { respondent read anticigarette Information on newspaper and/or Magazines, } 0= \\
\text { otherwise }\end{array}$ & 0.40 & 0.025 & 0.30 & 0.071 \\
\hline KCigSk & $1=$ respondent has the knowledge of Cigarette smoking, $0=$ otherwise & 0.96 & 0.010 & 0.82 & 0.066 \\
\hline PCigSk & $1=$ respondent perceive cigarette smoking to be addictive, $0=$ otherwise & 0.99 & 0.004 & 0.98 & 0.012 \\
\hline OCigTx & $1=$ respondent in favour of tax increase on price of cigarette, $0=$ otherwise & 0.84 & 0.021 & 0.68 & 0.068 \\
\hline
\end{tabular}

${ }^{a}$ The percentage of the smoking sample population.

${ }^{\mathrm{b}}$ The standard deviation of the coefficient of each independent variable.

${ }^{\mathrm{c}}$ The average consumption weighted price of cigarettes per pack using the location pricing mechanism (urban and rural) and was assumed to affect both the smoking participation smoking intensity among men and women in the urban and rural.

${ }^{\mathrm{d}}$ The household wealth index which was obtained using the first principal component of several household asset ownership indicators (e.g. car, radio, cell phone, TV, clock etc.).

\section{Empirical Results}

The results showed that the price of cigarette did not significantly affect men's decision to participate or not to participate in smoking behavior. Therefore, there could be other factors that make men to smoke or not to smoke. The results, however, suggested that women with smoking habits were very responsive to changes in cigarette prices as compared to men with smoking habits which, therefore, shows that smoking participation among women can be reduced through price adjustments.

Tauras [21] also found that the price of cigarettes had a negative and statistically significant effect on smoking participation among men and women. As men spent more time in school, their participation in smoking significantly decreases but for women, their smoking participation decline insignificantly. Generally, those who are married are significantly more likely to smoke than those who are singles. It implies that the married men and women have a lot of responsibilities to do in taking care and providing for the children.

Both men and women who are employed had a significant and reducing effect on their smoking participation as compared to men and women who are unemployed. Smoking rules inside homes had a negative and significant effect on women decision to smoke but for men, smoking rules inside homes had an insignificant effect on men participation in smoking. The men with smoking policy in indoor workplace were significantly and more likely to participate in smoking as compared to women with smoking policy in indoor workplace.

In addition, men who read anticigarette information on newspapers and magazines were significantly less likely to smoke as compared to women. Most men and women agreed that cigarette smoking is very addictive and thus significantly increasing their participation in smoking. Overally, cigarette tax adjustment had a very significant and reducing effect on both men and women participation in smoking [3].

The effect of cigarette price on overall and men smoking intensity was positive and very significant, which implied that adjustment in cigarette prices do not affect their smoking intensities. Men had a higher and significant smoking intensity as compared to women [22]. The results also showed that consumption levels among men increases significantly with age. Spending more time in school has an insignificant effect on men smoking intensity. Having more children in a family had a very significant and reducing effect on men smoking intensity. It means that resources are spent on ministering to the needs of the children rather than smoking cigarettes.

Smoking policy at indoor work place, knowledge about cigarette smoking and reading anticigarette information on newspapers and magazines had a negative but insignificant effect on the overall smoking intensity and also specifically on male smoking intensity. Perception about cigarette smoking had a positive and significant effect on overall smoking intensity [10] whereas cigarette tax adjustment had a negative and significant effect on both the overall smoking intensity and men smoking intensity.

Table 2. General, Male and Female Smoking Participation

\begin{tabular}{ccccccc}
\hline Independent Variables & \multicolumn{2}{c}{$\begin{array}{c}\text { Smoking Participation } \\
\text { (General) }\end{array}$} & $\begin{array}{c}\text { Smoking Participation } \\
\text { (Male) }\end{array}$ & \multicolumn{2}{c}{$\begin{array}{c}\text { Smoking Participation } \\
\text { (Female) }\end{array}$} \\
\hline Cigprice & -0.012 & $(0.042)$ & 0.007 & $(0.046)$ & $-0.205^{* *}$ & $(0.089)$ \\
Gen & $1.751^{* * *}$ & $(0.170)$ & - & - & - & - \\
Age & $-0.272^{* *}$ & $(0.107)$ & $-0.288^{* *}$ & $(0.115)$ & -0.019 & $(0.235)$ \\
Age Squared & 0.0009 & $(0.001)$ & 0.001 & $(0.001)$ & -0.0004 & $(0.001)$ \\
lnAge & $8.849 * * *$ & $(2.230)$ & $9.238^{* * *}$ & $(2.368)$ & 3.276 & $(4.316)$ \\
Eduyears & $-0.054 * *$ & $(.0217)$ & $-0.054 * *$ & $(0.023)$ & -0.078 & $(0.059)$ \\
Hhsz & 0.036 & $(0.042)$ & 0.047 & $(0.046)$ & -0.049 & $(0.108)$ \\
Children & -0.061 & $(0.099)$ & -0.091 & $(0.106)$ & 0.092 & $(0.252)$ \\
\hline
\end{tabular}




\begin{tabular}{|c|c|c|c|c|c|c|}
\hline Children Squared & -0.005 & $(0.012)$ & -0.001 & $(0.013)$ & -0.031 & $(0.035)$ \\
\hline Mals $\geq 15$ & -0.039 & $(0.047)$ & -0.029 & $(0.050)$ & -0.172 & $(0.124)$ \\
\hline RelAct & 0.217 & $(0.246)$ & 0.239 & $(0.260)$ & 0.299 & $(0.353)$ \\
\hline Marstat & $-0.608 * * *$ & $(0.172)$ & $-0.594 * * *$ & $(0.192)$ & $-1.022 * * *$ & $(0.392)$ \\
\hline Wokstat & $-1.030 * * *$ & $(0.123)$ & $-0.968 * * *$ & $(0.134)$ & $-1.931 * * *$ & $(0.339)$ \\
\hline SRules & $-0.350 * *$ & $(0.177)$ & -0.273 & $(0.218)$ & $-0.775 * * *$ & $(0.297)$ \\
\hline Wlthndx & $-0.065 * *$ & $(0.031)$ & $-0.062 *$ & $(0.032)$ & -0.042 & $(0.101)$ \\
\hline SPolicy & $-0.371 * *$ & $(0.175)$ & $-0.372 * *$ & $(0.182)$ & -0.934 & $(0.715)$ \\
\hline HWLCgPkg & $0.671 * * *$ & $(0.124)$ & $0.694 * * *$ & $(0.144)$ & $0.900 * * *$ & $(0.264)$ \\
\hline ATC2007 & $0.390 * * *$ & $(0.119)$ & $0.369 * * *$ & $(0.130)$ & $0.785^{* * *}$ & $(0.257)$ \\
\hline AntiCig & $-0.331 * * *$ & $(0.126)$ & $-0.346 * * *$ & $(0.131)$ & -0.178 & $(0.308)$ \\
\hline KCigSk & $-0.393 * *$ & $(0.612)$ & $-0.459 * *$ & $(0.210)$ & -0.272 & $(0.479)$ \\
\hline PCigSk & $0.581^{* *}$ & $(0.290)$ & 0.464 & $(0.313)$ & - & - \\
\hline OCgTx & $-0.526 * * *$ & $(0.112)$ & $-0.447 * * *$ & $(0.116)$ & $-1.476^{* * * *}$ & $(0.307)$ \\
\hline Constant & $-23.06^{* * * *}$ & $(6.183)$ & $-24.092 * * *$ & (6.717) & 9.694 & (14.10) \\
\hline
\end{tabular}

$1)^{*}, * *, * * *$ indicate that the coefficient is statistically significant at p-values $<0.1,<0.05$, and $<0.01$ of the two-tailed test respectively. 2) Standard errors are in parenthesis.

Table 3. General and Male Smoking Intensity

\begin{tabular}{|c|c|c|c|c|}
\hline \multirow{2}{*}{$\frac{\text { Independent Variables }}{\text { Cigprice }}$} & \multicolumn{2}{|c|}{ General Smoking Intensity } & \multicolumn{2}{|c|}{ Male Smoking Intensity } \\
\hline & $0.133^{* * *}$ & $(0.043)$ & $0.125 * * *$ & $(0.044)$ \\
\hline Gen & $0.583^{* *}$ & $(0.272)$ & - & - \\
\hline Age & $0.236^{* *}$ & $(0.092)$ & $0.201 * *$ & $(0.093)$ \\
\hline Age Squared & $-0.001 * *$ & $(0.001)$ & $-0.001^{*}$ & $(0.001)$ \\
\hline $\ln A g e$ & $-5.167 * * *$ & (1.898) & $-4.495 * *$ & (1.919) \\
\hline Eduyears & $0.053 * *$ & $(0.025)$ & 0.0446 & $(0.027)$ \\
\hline Hhsz & $0.328 * *$ & $(0.156)$ & $0.329 * *$ & $(0.162)$ \\
\hline Hhsz squared & -0.023 & $(0.015)$ & -0.022 & $(0.015)$ \\
\hline Children & $-0.454 * * *$ & $(0.161)$ & $-0.429 * * *$ & $(0.164)$ \\
\hline Children Squared & $0.043^{*}$ & $(0.022)$ & $0.040 *$ & $(0.022)$ \\
\hline Mals $>=15$ & 0.080 & $(0.151)$ & 0.073 & $(0.159)$ \\
\hline Mals $>=15$ Squared & -0.040 & $(0.036)$ & -0.040 & $(0.036)$ \\
\hline RelAct & 0.344 & $(0.289)$ & 0.373 & $(0.297)$ \\
\hline Marstat & $0.585^{* *}$ & $(0.267)$ & $0.514 * *$ & $(0.277)$ \\
\hline Wokstat & $-0.659 * * *$ & $(0.140)$ & $-0.679 * * *$ & $(0.137)$ \\
\hline SRules & -0.345 & $(0.205)$ & $-0.403 *$ & $(0.221)$ \\
\hline Wlthndx & -0.085 & $(0.056)$ & -0.081 & $(0.058)$ \\
\hline SPolicy & -0.224 & $(0.204)$ & -0.223 & $(0.204)$ \\
\hline HWLCgPkg & 0.102 & (0.167) & 0.124 & $(0.174)$ \\
\hline ATC2007 & $0.631 * * *$ & (0.189) & $0.665^{* * *}$ & (0.198) \\
\hline AntiCig & -0.329 & $(0.221)$ & -0.287 & $(0.227)$ \\
\hline KCigSk & -0.262 & $(0.225)$ & -0.271 & $(0.223)$ \\
\hline PCigSk & $0.476^{* * * *}$ & $(0.170)$ & $0.444 * * *$ & (0.169) \\
\hline
\end{tabular}

1) * Statistically significant at 0.10 level; ** at the 0.05 level; at the 0.01 level (two tailed test)

2) The values in parenthesis are the standard errors.

3) The smoking intensity results for females are not tabulated in the table because of the infinitesimal coefficient values which was as a result of the small sample size of female smokers as compared to the male smokers. 


\section{Conclusion}

Gender plays a key role in determining the probability of smoking participation and smoking intensity among the households. Also, Years spent by an individual in their education reduce their probability to participate in smoking behaviours especially for both men and women [23]. Work status and smoking policy at indoor work places helps to reduce both the smoking participation for both men and women. However, smoking policy at indoor workplaces has shown not to have any significant declining effect in men smoking intensity.

Tax adjustments in cigarette has shown to be the most effective tool in reducing the probability of smoking participation and level of smoking intensity among men and women [3]. Promoting the education of health effects of smoking habits in each level of schooling will also boost quitting and in turn reduce the quantity smoked among the smokers. The government should promote health counselling on effects of cigarette use for the married through community health care facilities and thus help to discourage smoking habits.

Strengthening the adherence to smoking policy in indoor work places discourage smoking participation and cause reduction in level of smoking intensity among those employed in either government offices, non-governmental organization and even in private institutions. Continuous analysis and evaluation of the cigarette tax system in to promote the decline in smoking participation and, therefore, reduction in level of smoking intensity among the users, [24] which is not be sufficient. Therefore, implementing a consolidated approach such as WHO MPOWER Package can be effective in achieving the reduction in smoking participation and smoking intensity.

\section{Acknowledgements}

This study was supported by a grant from Center for Tobacco Control in Africa, Uganda - International Development and Research Center, Canada.

\section{Declaration of Competing Interest}

The authors declare that they have no known competing financial interests or personal relationships that could have appeared to influence the work reported in this paper.

\section{References}

[1] WHO (2012). Kenya: Report Card on the WHO Framework Convention on Tobacco Control.

[2] Eriksen M., Mackay J. \& Schluger N., et al., (2015). The Tobacco Atlas (5th ed.). Atlanta: American Cancer Society and New York: World Lung Foundation.

[3] Chaloupka, F. (1991). Rational Addictive Behavior and Cigarette Smoking. Journal of Political Economy, 99(4), 722-742. doi:10.1086/261776.

[4] WHO (2010). The Abuja Declaration ten years on. Abuja: World Health Organization.

[5] Kiringai J., Ndung'u N. \& Karingi S., et al., (2002). Tobacco Excise tax in Kenya: An Appraisal Discussion, Paper No 21, Kenya Institute of Public Policy Research and Analysis (KIPPRA), Nairobi, Kenya.

[6] WHO. (2008). Report on the Global Tobacco Epidemic. Geneva: World Health Organization.

[7] Gaziano, T. A., \& Pagidipati, N. (2013). Scaling Up Chronic Disease Prevention Interventions in Lower- and Middle-Income Countries. Annual Review of Public Health, 34(1), 317-335. doi:10.1146/annurev-publhealth-031912-114402

[8] GATS (2014). Global Adult Tobacco Survey. Kenya Factsheet.

[9] KNBS (2014). Global Adult Tobacco Survey. Available Online: https://www.knbs.or.ke/?p=370. (Accessed on 4 Jan 2015).

[10] Guindon G., Emmanuel P. \& Anne M., et al., (2003). Higher tobacco prices and taxes in south-east Asia. HNP Discussion Paper, No.11, World Bank.

[11] Yurekli, A. A., \& Zhang, P. (2000). The impact of clean indoor - air laws and cigarette smuggling on demand for cigarettes: an empirical model. Health economics, 9(2), 159-170. doi:10.1002/(SICI)1099-1050(200003)9:2<159::AIDHEC499>3.0.CO;2-T.

[12] Chaloupka F. \& Warner K. E. (2000). The economics of smoking, In Culyer A. J. \& J. P. Newhouse, eds, Handbook of Health Economics, Vol. 1B, Elsevier Science, Amsterdam, pp. 1539 (1627).

[13] Townsend, L., Flisher, A. J., Gilreath, T., \& King, G. (2006). A systematic literature review of tobacco use among adults 15 years and older in sub-Saharan Africa. Drug and Alcohol Dependence, 84(1), 14-27. doi:10.1016/j.drugalcdep.2005.12.008

[14] Busch, S., Jofre-Bonet, M., Falba, T., \& Sindelar, J. (2004). Tobacco Spending and its Crowd-Out of Other Goods. doi:10.3386/w10974. 
[15] Gajalakshmi, V., Peto, R., Kanaka, T. S., \& Jha, P. (2003). Smoking and mortality from tuberculosis and other diseases in India: retrospective study of 43000 adult male deaths and 35000 controls. The Lancet, 362(9383), 507-515. doi:10.1016/s0140-6736(03)14109-8.

[16] John, R. M. (2005). Tobacco consumption patterns and its health implications in India. Health Policy, 71(2), 213-222. doi:10.1016/j.healthpol.2004.08.008.

[17] Rani, M. (2003). Tobacco use in India: prevalence and predictors of smoking and chewing in a national cross sectional household survey. Tobacco Control, 12(4), 4e-4. doi:10.1136/tc.12.4.e4.

[18] Zulu, R., Siziya, S., \& Nzala, S. (2009). Tobacco smoking prevalence among in-school adolescents aged 13-15 years: baseline for evaluation of the implementation of the FCTC in Lusaka district, Zambia. Medical Journal of Zambia, 35(3). doi:10.4314/mjz.v35i3.46527

[19] Cragg, J. G. (1971). Some statistical models for limited dependent variables with application to the demand for durable goods. Econometrica (pre-1986), 39(5), 829-844.

[20] Mao Z., Hsieh C. \& Hu T., et al., (2000). The Demand for Cigarettes in China. Chengdu, Sichuan, China: West China Medical Sciences University.

[21] Tauras, J. A. (2005). An empirical analysis of adult cigarette demand. Eastern Economic Journal, 31(3), 361-375.

[22] Uguru, N. P., Mbachu, C., Ibe, O. P., Uguru, C. C., Odukoya, O., Okwuosa, C., \& Onwujekwe, O. (2015). Investigating Male Tobacco Use and Expenditure Patterns across Socio-Economic Groups in Nigeria. PLOS ONE, 10(4), e0122021. doi:10.1371/journal.pone.0122021.

[23] Alam, A. Y., Iqbal, A., Mohamud, K. B., Laporte, R. E., Ahmed, A., \& Nishtar, S. (2008). Investigating socio-economicdemographic determinants of tobacco use in Rawalpindi, Pakistan. BMC Public Health, 8(1), 50-59. doi:10.1186/1471-24588-50.

[24] Mushtaq, N., Williams, M. B., \& Beebe, L. A. (2012). Concurrent Use of Cigarettes and Smokeless Tobacco among US Males and Females. Journal of Environmental and Public Health, 2012, 1-11. doi:10.1155/2012/984561. 